\title{
Feelings Which Strike a Chord, and Chords Which Strike a Feeling
}

\author{
Bernd Willimek ${ }^{1}$, Daniela Willimek ${ }^{2}$ \\ ${ }^{1}$ German Society for Music Psychology, Wuerzburg, Germany \\ ${ }^{2}$ University of Music, Karlsruhe, Germany \\ Email: willimek.danae.discs@t-online.de
}

How to cite this paper: Willimek, B. and Willimek, D. (2017) Feelings Which Strike a Chord, and Chords Which Strike a Feeling. Open Journal of Acoustics, 7, 10-17. https://doi.org/10.4236/oja.2017.71002

Received: October 11, 2016

Accepted: February 3, 2017

Published: February 6, 2017

Copyright $\odot 2017$ by authors and Scientific Research Publishing Inc. This work is licensed under the Creative Commons Attribution International License (CC BY 4.0).

http://creativecommons.org/licenses/by/4.0/

\begin{abstract}
The first part of this article addresses the main premise of the Theory of Musical Equilibration. It states that in contrast to previous hypotheses, music does not directly describe emotions: instead; it evokes processes of the will which the listener identifies with. It is not until these processes are experienced that music appears to take on an emotional character. The second part of the article focuses on demonstrating the emotional nature of musical harmonies. The Basic Test and the Rocky Test are presented. These tests were designed to find correlations between chords and scenes from fairy tales as well as emotional terms. $86 \%$ of the participants correlated the musical selection to the emotion outlined by the Theory of Musical Equilibration the authors developed in this context.
\end{abstract}

\section{Keywords}

Music and Emotions, Theory of Musical Equilibration,

Strebetendenz-Theorie, Chords, Music Therapy, Music Theory

\section{Introduction}

The correlation between music and emotions is not something we think about much until we consider what music really is. Music is nothing other than a series of oscillating molecules in the air. People like to make the self-evident statement that music is an international language, but science has still not been able to provide an explanation that deconstructs the nature of this language. To the best of our knowledge, the theory of Musical Equilibration [1] (known in the original German as the Strebetendenz-Theorie [2]) is the first to create a psychological paradigm which explains the emotional effects of music. It breaks down musical sequences into one of their most essential components harmonies and directly uses this material as the basis of its argumentation. Between 1997 and 2012, over 
2100 participants at German schools in Europe, Asia, Australia, North and South America took part in studies on the Theory of Musical Equilibration [1]. The participants included members of the Vienna Boys Choir. The results of the research offer empirical validation of the Theory of Musical Equilibration and show clear-cut parallels to the statements asserted by this Theory. More detailed information about the Theory and the methodology of our research can be found in our primary publication, Music and Emotions-Research on the Theory of Musical Equilibration [1].

\section{The Theory of Musical Equilibration}

The central premise of the Theory of Musical Equilibration is that music does not directly elicit emotions; instead, it communicates processes of the willprobably anchored in overtones-which the listener identifies and then interprets emotionally. To a certain extent, the basic assertion of the Theory of Musical Equilibration is a revised interpretation of Ernst Kurth's [3] descriptions of leading notes. But in contrast to Ernst Kurth, the Theory of Musical Equilibration interprets the perception of leading notes as a phenomenon in which the listeners identify with the desire not to change the leading notes. Two examples of this can be seen below in 2.1 and 2.2 .

\subsection{The Major Tonic}

To demonstrate, we will use the major chord C-E-G, where the leading tone is the E. Upon hearing a major chord (Figure 1) the listener will identify with the will that communicates the idea, "Yes, I want to". It is for this reason that a minor tonic expresses a sense of sober-minded contentment. In correspondence, the Ullstein dictionary of music [4] writes that the sound of the major tonic is "affirming". The Moser Dictionary of Music [5] states, "There is a great deal of truth to the statement that major chords sound happy and minor chords sound sad, despite the primitive nature of the idea."

\subsection{The Minor Chord}

Upon hearing a minor chord, such as C, Eb and G (Figure 2), the listener will identify with the will that communicates the idea "No more!" because of the

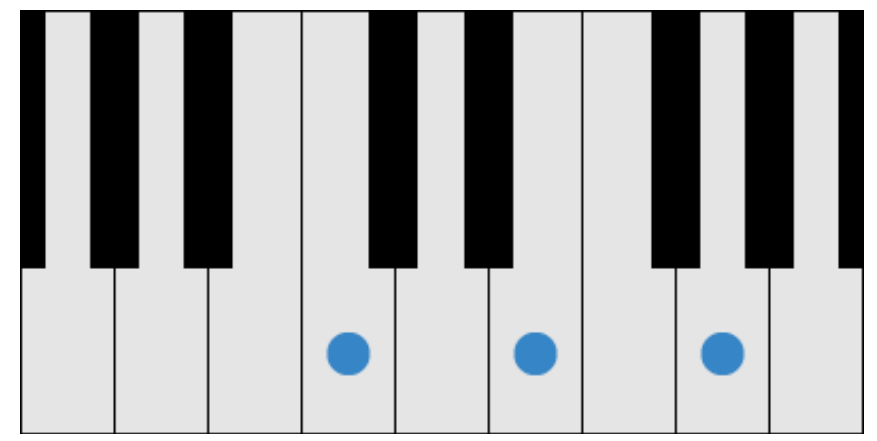

Figure 1. The Theory of Musical Equilibration states that when we hear a major chord, we identify with the content, "Yes, I want to!". 


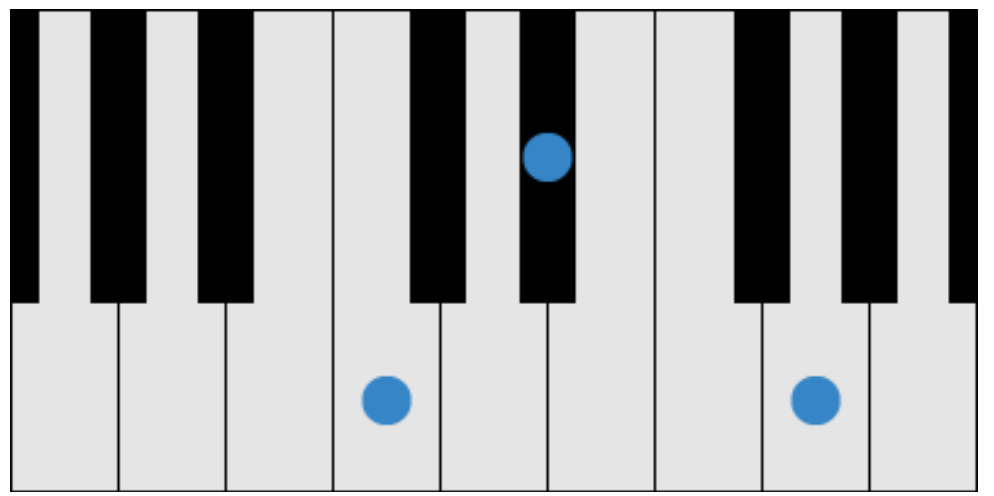

Figure 2. According to the Theory of Musical Equilibration, a minor chord causes us to identify with the will which says, "No more!". The minor chord can sound sad when the music is quiet and angry when it is loud.

"clouded" leading-note E flat. It is for this reason that the minor chord can be experienced as a statement of sorrow or anger, depending on whether the minor chord is played softly or loudly. The distinction here is the same as that between someone whispering the words "No more!" or screaming them. When spoken softly, the words sound sad, but when spoken loudly, the same words sound furious. The same thing is true of minor chords: a quiet minor chord sounds sad, whereas a loud one sounds angry. Correspondingly, the Moser dictionary of music [6] describes the nature of the minor chord as "the major being clouded by the minor" and the Ullstein dictionary of music [7] defines a minor chord as a "suppressed major".

Similarly, the Theory of Musical Equilibration also explains the emotional nature of other harmonies, some of which are illustrated below in 3.1.1. ff. By elucidating the myriad possibilities of how both anticipated and perceived harmonies interact, the Theory creates a framework for musically depicting even complex harmonic structures and processes of the will. Consequently, this may move us closer to answering the question about the emotional perception of musical harmonies by using the following tests to confirm the hypotheses.

\section{The Tests}

In 1996, Bernd and Daniela Willimek began conducting surveys to learn how children judged the effects of chords. They used the data from these surveys as the basis for a wide-scale study in which over 2100 children from four continents participated in musical preference tests from 1997 to 2011 . These tests were designed to find correlations between scenes from fairy tales and emotional terms that describe chords.

\subsection{Open Questions Provided Promising Answers}

Initially the authors worked with open-ended questions about chords and asked the test participants to associate freely. For example, the authors played different chords and harmonies and then asked the children questions such as the following: What does this music make you think of? A scene from a movie? A word? A 
situation? Can you describe these sounds somehow? Their answers always conspicuously clustered around particular kinds of emotional content.

\subsubsection{The Diminished Seventh Chord}

A diminished seventh chord (Figure 3) played at greater volume is described using terms related to panic or fear, such as "horrible", "someone trying to run away from a monster", and/or "a creepy story" (cf. Chapter 2.4, [1]). On a similar note, author and director Reinhard Kungel [8] describes the use of the diminished seventh chord by saying, "Consisting of three minor thirds, a diminished seventh chord is frequently used in film music to generate tension and cause people to shudder and be startled."

\subsubsection{The Subdominant with an Added Sixth}

The subdominant with an added sixth (Figure 4) is an expression of profound togetherness, a feeling of warmth and emotional solace. Wikipedia [9] states that "modulation into the subdominant key often creates a sense of musical relaxation." Upon hearing a subdominant with an added sixth, the children who took the test mentioned images of emotional warmth and security and made statements such as "the sound would go well with a happy ending", "resting, standing still", "like a perfect world, somehow a meadow of flowers, girls picking flowers", or "a love story". In the tests, a tonic chord was played first so that the subdominant was clearly identifiable as such.

\subsubsection{The Whole-Tone Scale}

Music theorists are universal in their agreement about the role of leading-notes in the whole-tone scale. They state that leading-notes are nearly non-existent.

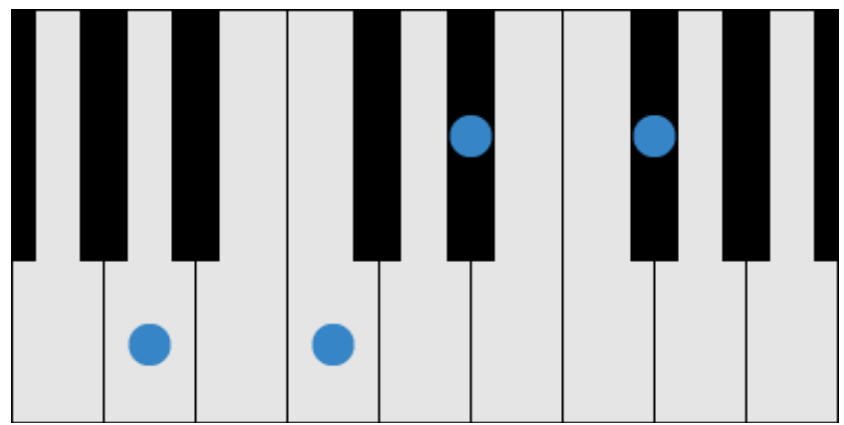

Figure 3. When played loudly, the diminished seventh chord is linked to feelings of panic and fear.

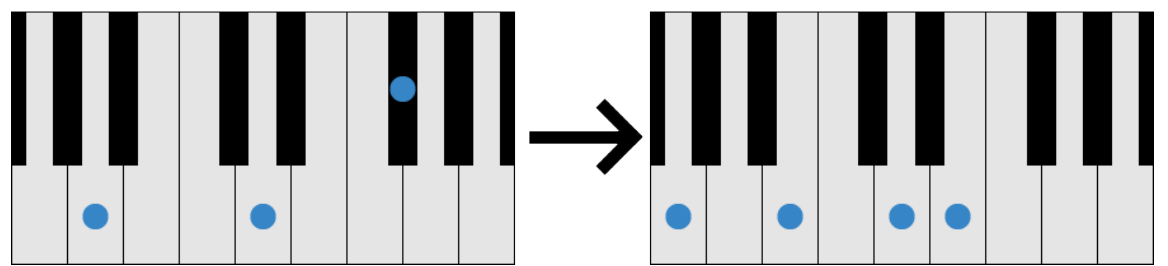

Figure 4. The major subdominant with an added sixth (right) suggests ideas such as emotional warmth and a happy ending. Here the subdominant was preceded by the tonic (left) to clearly establish it as a subdominant. 
Diether de la Motte [10] writes, "Every note of the scale can be played with every other: there is no resolution to this dissonance." Using the Theory of Musical Equilibration to interpret whole-tone sequences leads us to the following observation: because of the missing leading notes, it is extremely difficult to pinpoint the focus of the will. The character of the whole-tone scale corresponds to the mental image of floating weightlessly. When the test subjects heard a whole-tone scale (Figure 5), they stated that it evoked visions of floating weightlessly as "under water", "in outer space", or "in a dream".

\subsubsection{Natural Minor}

Music in natural minor (Figure 6) does not sound sad, instead, it sounds adventurous or courageous. It inspires thoughts of adventure and tension. In response to the natural minor, the children who took the test said it sounded "exciting", "adventurous", "like a thriller", or "something with cowboys".

\subsubsection{The Augmented Chord}

A typical characteristic of the augmented chord (Figure 7) is the ambiguous nature of the perceptible effects of leading-notes. Diether de la Motte [11] writes: "Context is what decides whether the $\mathrm{C}$ or the $\mathrm{G} \#$ is dissonant in the triad E-G\#-C". An augmented chord has conflicting forces of leading-notes, whichaccording to the Theory of Musical Equilibration-means that the emotional character it evokes can vary. In other words, when we hear an augmented chord, we cannot clearly identify with a sense of will that the chord expresses. Listeners are left questioning. This chord is used to communicate amazement, surprise or astonishment. In response to the augmented chord, the children said it sounded like "when the thorns grow around Sleeping Beauty's castle", "something unusual", or "a fairy charm".

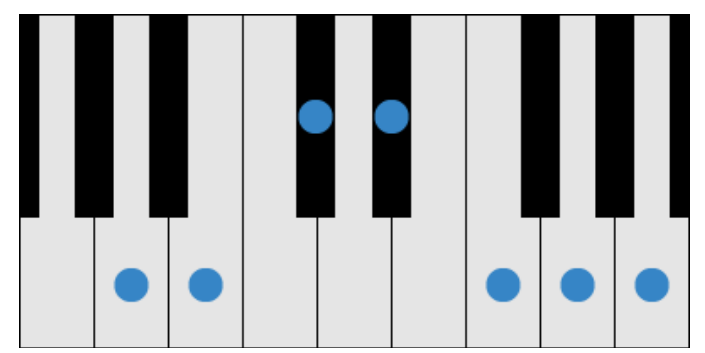

Figure 5. The notes of the whole-tone scale are associated with floating and weightlessness, e.g. being under water, in outer space or in a dream.

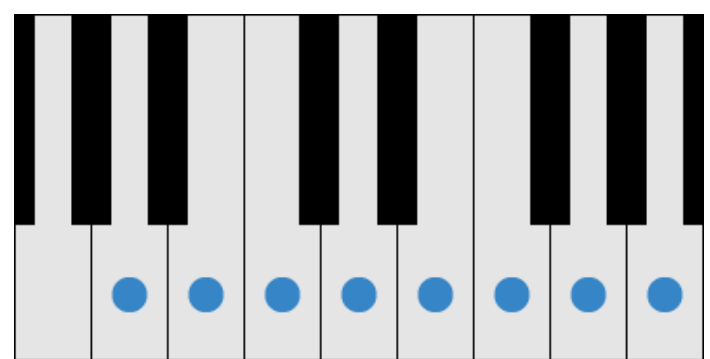

Figure 6. The natural minor gives children a sense of adventure and tension. 


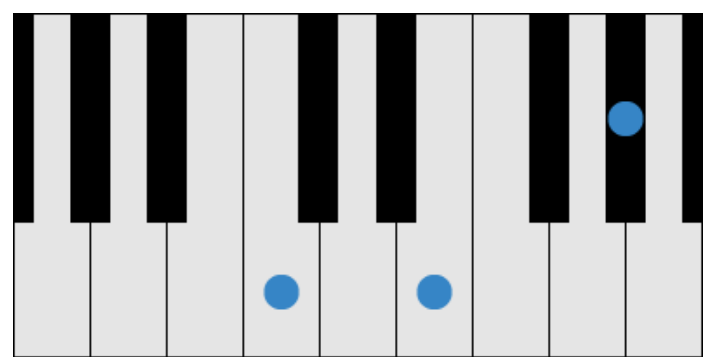

Figure 7. Children state that augmented chords convey a sense of astonishment, magic and wonder.

\subsection{The Rocky Test Quantifies the Correlations between Chords and Fairy-Tale Scenes}

The data from the open questions described in 3.1 prompted the authors to develop a survey they called the Rocky Test. It consists of a fairy tale called "Sleeping Beauty and Prince Rocky". The story involves eight scenes, each of which is scored by two different musical selections that are intended to communicate the following emotions by chords: astonishment (augmented chord), a feeling of forward motion (dominant), weightlessness (whole-tone scale), despair (diminished seventh chord), courage (natural minor), emotional warmth (added sixth in a major subdominant), a wistful farewell (subdominant with a major seventh) and loneliness (added sixth in a minor subdominant). At each phase of the test, subjects chose between two pieces of music, one of which emphasized one of the types of chords listed above. The participants listened to the fairy tale and wrote down which piece of music best matched the scene in question. The test took a maximum of 15 minutes. The preference test was held with over 2100 participants on four different continents, predominantly with school groups of different ages. Here too, remarkable correlations were seen in the preferences they expressed for certain pieces of music. The pieces which were based on that harmonic sequence were overwhelmingly preferred. On average, $86.96 \%$ of the answers correlated with each other as well as with the premise of the Theory of Musical Equilibration [12].

\subsection{Can Emotional Concepts Be Linked to Chords?-The Basic Test}

The outcome of the Rocky Test inspired the authors to design a second test which would examine whether there is a correlation between chords and emotions. This was achieved by simply juxtaposing chords and emotional concepts, without the interim step of a fairy tale. To this end, the authors created the Basic Test, which uses simple means to examine people's preferences for certain chords. The pieces of music were kept to a minimum, consisting either of intervals, a single chord, very few chords, or very short cadences: despair (diminished seventh chord), wandering (dominant), loneliness (added sixth in a minor subdominant), magical transformation (augmented chord), dream of summer (subdominant with a major seventh), adventurous (natural minor), angry (minor chord is repeated several times and grows louder), threatening (minor sixth), comforting (added sixth in a major subdominant) and under water 
(whole-tone scale). The rate of matches was extremely high in the Basic Test as well: $92.17 \%$ [13].

\subsection{Can These Insights Be Applied in Music Therapy?}

In a pilot study held at a children's hospital, the authors observed a complementary phenomenon. They administered the Rocky Test to 48 children at a pediatric hospital, the Klinik für Kinderneurologie und Sozialpädiatrie Kinderzentrum, in Maulbronn, Germany, from July 2012 to January 2013. The results of the research conducted there also showed high levels of correlation in terms of the preferred music sample; however, participants with autism or social disorders responded differently to some scenes (such as the one about emotional warmth) than the children who did not have these conditions. No valid conclusions can be extrapolated from the data this pilot study generated, however, due to the small sample size. Further trials could provide insights into whether the Rocky Test and Basic Test provide options for use in music therapy.

\section{Conclusions}

The manuscript "Feelings which strike a chord, and chords which strike a feeling" endeavors to show that there is a correlation between chords and emotions. Chords can evoke different and even contradictory emotions. Throughout history, music has been and is still used for therapeutic purposes, including educational ones.

Musical harmonies create emotional effects, and this issue is as relevant today as ever. Centuries of composers have been using harmonic structures in keeping with the observations described in the Theory of Musical Equilibration, which is quite a remarkable phenomenon. This gives researchers an endless field of new activities and a wide range of opportunities due to the rich scope of untapped material. The Theory of Musical Equilibration is intended to inspire further interest in one of the most exciting aspects of musicology: the emotional response to musical harmonies.

\section{References}

[1] Willimek, D. and Willimek, B. (2013) Music and Emotions-Research on the Theory of Musical Equilibration. http://www.willimekmusic.de/music-and-emotions.pdf

[2] Willimek, D. und Willimek, B. (2011) Music und Emotionen-Studien zur Strebetedenz-Theorie. http://www.willimekmusic.de/musik-und-emotionen.pdf

[3] Kurth, E. (1930) Musikpsychologie. Olms, Hildesheim, 13.

[4] Herzfeld, F. (1965) Ullstein-Musiklexikon. Ullstein, Berlin, 351.

[5] Moser, H.M. (1955) Musiklexikon, Vol. 2. 4th Edition, Sikorski, Hamburg, 794,

[6] Moser, H.M. (1955) Musiklexikon, Vol. 2. 4th Edition, Sikorski, Hamburg,793.

[7] Herzfeld, F. (1965) Ullstein-Musiklexikon. Ullstein, Berlin, 351.

[8] Kungel, R. (2008) Filmmusik für Filmemacher. Dpunkt Verlag, Heidelberg, 77.

[9] Wikipedia (2013) Subdominant. https://en.wikipedia.org/wiki/Subdominant 
[10] De la Motte, D. (1938) Harmonielehre. 4th Edition, Bärenreiter, Kassel, 35.

[11] De la Motte, D. (1938) Harmonielehre. 4th Edition, Bärenreiter, Kassel, 54.

[12] Willimek, D. and Willimek, B. (2013) Music and Emotions-Research on the Theory of Musical Equilibration. Willimek, Bretten, 28-39.

[13] Willimek, D. and Willimek, B. (2013) Music and Emotions-Research on the Theory of Musical Equilibration. Willimek, Bretten, 41-66.

Submit or recommend next manuscript to SCIRP and we will provide best service for you:

Accepting pre-submission inquiries through Email, Facebook, LinkedIn, Twitter, etc. A wide selection of journals (inclusive of 9 subjects, more than 200 journals) Providing 24-hour high-quality service User-friendly online submission system Fair and swift peer-review system Efficient typesetting and proofreading procedure Display of the result of downloads and visits, as well as the number of cited articles Maximum dissemination of your research work

Submit your manuscript at: http://papersubmission.scirp.org/

Or contactoja@scirp.org 